\author{
Micheline Cariño* \\ Luis Alberto González** \\ Erín Castro***k \\ Esteban Ojeda*k*k
}

\title{
VIEJA Y NUEVAS CONCEPCIONES DE LA FRONTERA: APORTES TEÓRICOS Y REFLEXIONES SOBRE LA HISTORIA SUDCALIFORNIANA
}

\begin{abstract}
RESU MEN
A nte la complejidad de la globalización, la historia de los fenómenos fronterizos permite entender las fases y los mecanismos que desarticularon el paradigma del Estado-nación para conformar el demundialización. En esteensayo seanaliza, desde la perspectiva dela historia, la concepción cultural, social y económica dela frontera. Primeramente, se hace una revisión de los principales conceptos y autores considerados indispensables para abordar la problemática fronteriza. Posteriormente, y en lo queseconsidera la mayor aportación deestedocumento, se propone una revisión del pasado subcaliforniano a partir de los conceptos constitutivos del nuevo paradigma defrontera.
\end{abstract}

\section{A BSTRA CT}

In the wake of the complexity of globalization, the history of border phenomena allows for the understanding of the stages and mechanisms that actually disarticulated the State-N ation paradigm in order to give way to the paradigm of worldlization. From a historic perspective, this essay analyzes the cultural, social, and economic conception of the border. First off, a review of the chief concepts and authors deemed indispensable in order to address the border problems is done. Subsequently, in what is considered the most important contribution of this document, a review of the Suothern Californian past on the basis of the concepts that constitute the new border paradigm is proposed.

\footnotetext{
* Profesora investigadora de tiempo completo en la Universidad Autónoma de Baja CALIFORNIA SUR. CORREO ELECTRÓNICO: irda@mexico.com

** Estudiante de licenciatura en Historia en la Universidad Autónoma de Baja CALIFORNIA SUR. CORREO ELECTRÓNICO: coqui@balandra.uabcs.mx

*** LICENCIADO EN HISTORIA POR LA UABCS, ACTUALMENTE ESTUDIA EL DOCTORADO EN HISTORIA EN LA SORBONNE EN PARÍS, FRANCIA. CORREO ELECTRÓnICO: Castroliera@wanadoo.fr * H*LICENCIADO EN HISTORIA POR LA UABCS, Y MAESTRO EN HISTORIA REGIONAL DE LA MISMA INSTITUCIÓN.
} 


\section{INTRODUCCIÓN}

Mundialización es el paradigma que caracterizará al nuevo milenio. Estesiglo inició con la primera conflagración a escala mundial y termina saludando a la aldea global. ¿Contradictorio?, ¿congruente con la historia magister vita?, ¿fase evolutiva y extrema del capitalismo? Planteamientosque requieren la reflexión interdisciplinaria y multidisciplinaria para su esclarecimiento.

Ante la complejidad de la global ización, la historia tiene un lugar privilegiado para analizar los procesos que a ella condujeron. Particularmente, la historia de los fenómenos fronterizos permite entender las fases y los mecanismos que desarticularon el paradigma del Estado-nación para conformar el dela mundialización.

Éstees un debatequelos más destacados especialistas delas ciencias humanas abordan en la actualidad (Sciences Humaines, 1997). En ninguna medida el presenteensayo aspira a esas al turas, tampoco nos dejamos seducir por la moda. Nuestro esfuerzo recae en tratar de analizar, desde la perspectiva de la historia, la concepción cultural, social y económica dela frontera, por lo quenos correspondeaportar a nuestros colegas - y a todos los interesados- los criterios queconsideramos insoslayables desde la perspectiva de Clío. Así, desdeel punto de vista teórico no aportamos ninguna novedad, sólo nos limitamosa identificar y presentar a los estudiosos que, a nuestro criterio, deben ser estudiados.

Estetrabajo tienemás mérito en su matiz empírico, ya queal analizar la historia regional desde la perspectiva anterior, proponemos una revisión del pasado sudcaliforniano a partir de los conceptos constitutivos del nuevo paradigma de frontera.

Iniciamos estetrabajo discutiendo la inoperancia del viejo concepto de frontera; lo que es evidente ante la actual mundialización, pero que en Baja California no es un proceso reciente sino una constante histórica. Situación esta última que justifica - académica y social mente- aún más la imperiosa necesidad dereflexionar en torno a los múltiples enfoques de la nueva concepción de frontera. En este ensayo hemos seleccionado tres de ellos: el geográfico-ecológico, la identidad cultural y la economía. 
La definición tradicional de frontera como la línea divisoria internacional que indica la demarcación geográfico-política entre un país y otro, ha quedado rebasada desde el punto de vista académico. Un nuevo concepto va más allá deesa simpleidea, eincluyeelementos que analizan las condiciones históricas, económicas, políticas y culturales que llevaron a que esa línea quedara establecida y a sus implicaciones globales. No es posible estudiar a la frontera como al go inertey unilateral, sino como el resultado de las complejas relaciones de los hombres en su afán de apropiación territorial para extender su poder político y dominación económica, alentados por fuertes acicates ideológicos justificadores de la expansión. El análisis histórico de la frontera que parte de esa óptica, implica necesariamente verla como un punto de conflicto, donde confluyen una serie de problemas e intereses de ambos lados de la línea.

En el periodo de la conquista y colonización española en América, especial mente en su expansión hacia el noroeste, la frontera fuetierra abierta y la demarcación era meramente simbólica. La misión y el presidio fueron las instituciones puntaleras que abrieron brecha para extender el dominio español en una tierra de guerra con los grupos nómadas y seminómadas que habitaban esos lugares. La frontera española, pese a su carácter conquistador y destructor, actuó siempre con criterios deinclusión delas culturas indígenas que seencontraban en los territorios dominados. La principal causa de esta asimilación fuela endémica escasez demano deobra, aunquelos indígenas también fueron la clientela potencial para difundir las ideas religiosas que justificaban la conquista (Weber en Solano y Bernabeu, 1991:70-71).

La frontera angloamericana, por su parte, tuvo esas mismas premisas expansivas, pero aplicó un criterio de exclusión con las culturas aborígenes. Su tendencia fue aniquiladora y pocas veces aislante, pero nunca incluyente. La preocupación de los estadounidenses era la dellevar el límitedesu expansión másallá del territorio ocupado por las trece colonias. 
Al sur deangloamérica y al norte dela A mérica española se abrían una inmensidad de tierras de frontera incitantes a la expansión. Los novohispanos fueron los primeros en ocupar gran parte de esas vastedades, pero no demarcaron ni sostuvieron un límite preciso que indicara sus dominios.

Con laindependencia, México heredó un amplio territorio cuya línea fronteriza septentrional era incierta. Esas áridas tierras norteñas poco pobladas pronto fueron motivo deacechanzas expansionistas y grandes controversias.

Los estadounidenses vieron en esastierras la posibilidad deextender sus dominios y, al amparo del Destino manifiesto, iniciaron el desplazamiento multidireccional de su frontera, pero especialmente hacia el sur de su territorio, de tal manera que el gran norte mexicano sufrió, durantetodo el siglo XIX, las disputas y amenazas expansionistas de los Estados Unidos. En 1836, México, ante la imposibilidad de defender exitosamente su territorio, tuvo que ceder forzosamente al reconocimiento dela independencia de Texas. Pocos años después, las circunstancias generadas por la invasión estadounidense de 1847, obligaron al gobierno de la república a firmar el Tratado de paz y amistad de Guadalupe Hidalgo, en el que se reconocía la pérdida de más dela mitad de nuestro suelo patrio.

Desde el punto de vista estadounidense, la frontera seguía siendo flexible, completamentelaxa, detal manera quese podía extender hasta dondeellos pudieran llegar; es decir, empujar la frontier constantemente hacia el sur. En efecto, el borderline no solamente rebasó los límites primigenios deTexas, sino queabarcó los territorios deArizona, Nuevo México y California, y no conformecon ello, bajó más allá, incluyendo ala M esilla, y después, todo lo que pudiera comerse del río Bravo. Así, la invasión militar selegitimó con el acuerdo diplomático de Guadalupe Hidalgo.

Para ese periodo, la frontera norte de México no implicaba el concepto detierra abierta a la expansión, sino mantener la línea divisoria internacional en su nueva posición sal vaguardando los territorios que, después de la guerra de 1847 y tras la venta de la Mesilla en 1853, seguían siendo mexicanos. La nueva zona fronteriza aún estaba poco poblada y permanecía bajo la constante amenaza de la frontier. 
Los esfuerzos del gobierno federal para frenar ese avance expansionista en el norte, se canalizaron fundamental mente hacia el poblamiento. El intento de trasladar personas del centro del país al nortey deestablecer colonias militares en la línea fronteriza, no siempre fue exitosa. Esta política fracasó, entre otras cosas, por la enorme distancia entreel centro y la frontera, así como por los escasos medios de comunicación y los constantes conflictos por los que atravesaba el país en el tránsito deconsolidar un gobierno estable. Por ello, durante mucho tiempo, las poblaciones de la frontera estuvieron al garete y resolvieron sus problemas económicos y políticos como mejor pudieron. La vigilancia y cuidado delalínea divisoriainternacional prácticamente quedo a la deriva. Constantemente el suelo mexicano era objeto de incursiones de bandoleros estadounidenses y las poblaciones fronterizas no sólo estaban prácticamenteabandonadas por el gobierno federal, sino quevivían en lazozobra por la acechanza del país vecino.

\section{REFLEXIONESEN TORNO AL CASO SUDCALIFORNIANO}

Baja California vivió exacerbadamente los problemas que planteó la definición de la frontera decimonónica. A las ya mencionadas características de los territorios norteños se agregaba su aislamiento, lo que dificultaba aún más la presencia y acción del gobierno federal. A simismo, la existencia desu largo frentemarítimo y sus ricos recursos naturales, fueron elementos que atrajeron de manera especial los intereses expansionistas estadounidenses.

Para resolver el problema de la falta de población en la zona fronteriza norte del país, el gobierno de Benito Juárez inició una política de colonización y de incentivación a la inversión extranjera. A sí justificó, en 1864, la autorización de una delas más controvertidas concesiones territoriales conocida con el nombrede "concesión Leese". Con ella otorgó amplios derechos a los concesionarios estadounidenses a cambio de un pago de cien mil dólares (Panian, en Ojeda, 1996:179). Entre otras cosas, los empresarios y comerciantes del país vecino debían colonizar una buena parte de Baja California, concretamente la zona de bahía Magdalena. La concesión Leese no pobló la zona pero sí explotó, intensiva eirracional mente, la orchilla, 
una epífita tintórea que abundaba en los Ilanos de Magdalena-Hiray (Cariño, 1995: 5-18).

Con el mismo pretexto de poblar la zona fronteriza y la península de Baja California en especial, el gobierno del general Porfirio Díaz inició también un programa de colonización y deslinde de tierras a cargo de las compañías deslindadoras, que con una extraordinaria facilidad obtenían los permisos para posesionarsedeextensas porciones detierra. Cuando las compañías eran nacionales, rápidamentetraspasaban sus propiedades a las extranjeras, de tal forma que en pocos años la mayor parte de la extensión territorial de la península bajacal iforniana estaba en manos de extranjeros; sólo se sal vaba una pequeña porción de la parteaustral del hoy estado de Baja Cal ifornia Sur. Al respecto, Pablo Herrera Carrillo (1976:10) estima que: "al finalizar el siglo XIX, la península de Baja California estaba prácticamente perdida para México. La inmensa mayoría de su territorio había caído en manos extranjeras mediantemaniobras y especulaciones delas llamadas compañías colonizadoras.

En la época de las concesiones, los peligros que cernían a la franja fronteriza deBaja Cal ifornia y ala península eran tan evidentes, quela frontera como línea divisoria internacional de facto fue recorrida hasta los límites de la actual municipalidad de Los Cabos, Baja California Sur. Aquí encontramos un claro ejemplo deuna concepción delafrontier, en tanto que un límite capaz de permitir el empuje hacia tierra ajena aunque ésta no estuviera vacía.

Tanto esta apreciación de las compañías colonizadoras como la invasión estadounidense a Baja California y las posteriores acciones filibusteras a tierras peninsulares, son ejemplos claros delasintenciones anexionistas quelos Estados Unidos tenía respecto a la península. Estas evidencias col ocan a Baja California y a Baja Cal ifornia Sur como tierra de frontera. Las invasiones militares como la guerra de 1847 y las gestiones diplomáticas, fijaron una línea divisoria internacional que bajo la óptica estadounidense marcaba el principio de las tierras por anexar y quepara México representaba un límitedifícilmentesostenible para el ejercicio desu soberanía.

En efecto, la acumulación de tierras a través de las compañías colonizadoras, aunado a la propaganda de la inminente anexión que 
se hacía en el país vecino del norte, hicieron de la península una imaginaria tierra de jauja naturalmente destinada a formar parte de Ios Estados Unidos. ${ }^{1}$

Demanera excepcional, desdeel siglo XIX Ia fronterabajacaliforniana abarca una zona de más de $1500 \mathrm{~km}$ de ancho, sin duda de las más vastas del mundo. Por ello, el concepto tradicional de frontera decimonónica es, a todas luces, inoperante para Baja California, pero no así el concepto defrontier.

Lainfluencia del expansionismo estadounidensequecon el Destino manifiesto afectaría a toda Latinoamérica, tuvo sus más evidentes repercusiones en Baja California, de tal manera que, a pesar de encontrarsetan al ejada dela línea divisoria internacional, la península siempre ha sido percibida, tanto por estadounidenses como por mexicanos, como una zona fronteriza, por lo que proponemos considerar a Baja Cal iforniaSur, con el viejo concepto defrontera, como una pseudofrontera.

Las reflexiones anteriores evidencian queel concepto decimonónico de frontera es inoperante para el estudio de regiones comparables a BajaCalifornia. El análisis delasimplicaciones geopolíticas, económicas, y culturales que tiene la permeabilidad de la línea divisoria internacional, conlleva a la reflexión en torno a nuevos conceptos defrontera, ya que la flexibilidad de la frontera no implica su inexistencia, por el contrario, remite a una real idad cuyas implicaciones afectan todas las esferas del quehacer y desarrollo socioeconómico. Por ello, en los próximos tres apartados analizaremos conceptos que permiten acercarseal nuevo paradigma de frontera.

${ }^{1}$ J. R. Southworth escribió, en 1899, un libro titulado Baja California ilustrada (1989) en el quecon exageraciones detodo tipo, señalaba que esta región era inmensamente rica y quesól o faltaba la mano dehombres emprendedores para obtener esa riqueza. Desde la introducción indicaba que "el principal objeto de su libro era atraer la atención de los capital istas inteligentes hacia el territorio de Baja California donde los enormes recursos eran manifiestos de la manera más completa", (Southworth, 1989:3). Esta obra tuvo gran circulación en varios estados de la unión americana. 
La primera frontera queel hombreconoció fueron los límites naturales a su reproducción social y a la expansión territorial de su grupo. La naturaleza dominó durantemilenios el devenir de la humanidad. Las posibilidades de sobrevivencia, primero, y de crecimiento después, dependieron dela capacidad de adaptación del hombre a su espacio. Esta adaptación fue el resultado de un proceso de conocimiento del potencial biótico y abiótico del espacio y de desarrollo del ingenio humano para diseñar estrategias que le permitieran convertir en recursos los elementos natural es dedicho potencial y en parteintegral de su territorio las características físicas del medio geográfico.

Es importantenotar quelas fronteras naturales siemprehan tenido un carácter global, circundante y no sól o vertical u horizontal, lo que contraviene a la definición clásica del término frontera, a saber: "la avanzada de un poder más periférico" (Guhl, 1991:7).

Fernand Braudel, el historiador del medio geográfico, explica que éste está constituido por cuatro complejos: el atmosférico, ${ }^{2}$ el hidrológico, ${ }^{3}$ el terrestre ${ }^{4} y$ el biótico. ${ }^{5} \mathrm{~A}$ través del tiempo, el conocimiento y el dominio de estos cuatro complejos han aportado al hombre la base geohistórica sobre la cual ha desarrollado una serie de estrategias civilizatorias para organizar su espacio, explotar de forma particular los recursos naturales y definir sus medios de apropiación territorial. La trama compleja que así se constituye es Ilamada por Braudel la civilización material (Braudel, 1979). Cada sociedad, aunque viva en

${ }^{2}$ Vientos, precipitaciones. clima, temperatura, etcétera.

${ }^{3}$ Ríos, mares, lagos, océanos.

${ }^{4}$ Que puede ser visto en términos horizontales (islas, penínsulas, continentes) y verticales (orografía).

${ }^{5}$ Formado por la flora y la fauna. 
medios geográficos similares y en la misma época, construye su propia civilización material o por lo menos da un cariz sui generis a ésta. La diversidad tan grande derelaciones quesecrean en el eterno y dialéctico juego deestímulo y respuesta entre la basegeohistórica y la civilización material, demuestran queeste enfoque ambiental ista de la historia no sólo se aparta del determinismo geográfico, sino que rompe por completo con él (Lepetit, 1996:39-48), de ahí que la geohistoria braudeliana ${ }^{6}$ sea fundamental para entender la formación y reconfiguración delas fronteras naturales quelas sociedades humanas han enfrentado durantemilenios.

Una visión menos alejada del determinismo geográfico - pero no por ello desdeñable - es la propuesta del origen de la civilización de Arnold Toynbee. Este historiador británico, amante de las grandes síntesis históricas, consideró quela capacidad para dominar el entorno era lo que permitía a una simple sociedad convertirse en una civilización. En consecuencia, las sociedades que no lograran invertir el papel avasallador de la naturaleza, no serían sino civilizaciones abortadas (Toynbee, 1991). Deesta manera, el origen dela civilización -y con éste el de la verdadera historia de la humanidad- es determinado por la superación de las fronteras naturales gl obales. El hombre civilizado no se enfrenta al medio geográfico, lo pone a su servicio. Sabemos que esta tesis, además de obsoleta, es peligrosa, sin embargo, no podemosnegar su arrol ladora presencia en la mentalidad de los siglos XIX y XX, así como la importancia que puedetener en el estudio histórico de las fronteras naturales (Veyret y Pech, 1993).

La idea de que la ciencia y la técnica otorgarían al hombre pleno dominio sobre la naturaleza y con éste la seguridad de su progreso permanente, dio origen a lo queFredricRatzel calificó como la economía de pillaje y desperdicio: la "rawbrichcrtaft". En una escala intensiva,

${ }^{6}$ En la que prevalecen los criterios de una geografía retrospectiva y el concepto de la larga duración histórica (Braudel, 1953:317-327). 
desde el siglo XVII hasta la actualidad, la civilización occidental se empeñó en extender su dominio al mundo entero para asegurar el crecimiento del capitalismo a través del control delos recursos naturales y humanos. Segestó, así, un fenómeno paradójico desdela perspectiva del análisis histórico de las fronteras. A medida quese el iminaban las fronteras naturales se erguían las fronteras político-administrativas. Para poder usar y abusar del potencial natural y humano decual quier región del planeta, la competencia entre las principales potencias capitalistas requería precisar la apropiación territorial de las zonas dominadas, de tal manera que el hombre moderno creyó que había vencido las fronteras naturales y que era necesario imponer un nuevo concepto de frontera para delimitar los territorios; concepto que será discutido en el siguiente apartado.

Por el momento es importanteretomar la cuestión dela eliminación de las fronteras naturales. Es evidente que la relación hombre/ naturaleza en la época contemporánea es radical mente diferente a la detodos los siglos anteriores en la historia dela humanidad. Más aún en la actual idad, cuando la tecnol ogía ha creado la cibernética modificando por completo los conceptos detiempo y espacio. La relación que el hombretienecon los complejos del medio geográfico es otra debido al transporte aéreo, a la comunicación satelital, al clima artificial, a la bioquímica, entre muchos otros. Nada parecería más evidente: el hombre ha vencido las fronteras naturales.

¿Pero sepodrían olvidar los efectos perversos del avancetecnológico e industrial? La grave crisis ambiental presente muestra que las fronteras naturales, si bien distintas, siguen imponiéndoseal desarrollo dela humanidad. Para entender estas nuevas fronteras se requiere un cambio dementalidad: no sólo vivimos en la Tierra sino vivimos dela Tierra, y ella tiene una dinámica que, por mucho, sobrepasa el conocimiento humano y su capacidad de dominio. LaTerrenourricière, ${ }^{7}$

${ }^{7}$ Traducción: la tierra nutricia. 
la biosfera, "el planeta viviente", son al gunas apelaciones queindican el surgimiento de esta nueva mentalidad, de esta nueva conciencia.

El primer paso está dado, sin embargo, aún no inicia la verdadera batalla que permitirá limitar, erradicar y, en el mejor de los casos, revertir los atentados que contra nuestra aldea global ha perpetuado la Raubwirtschaft (Raumolin, 1984:798-819). Esto precisa de un cambio profundo y complejo que transforme nuestra civilización material, nuestra economía y, por supuesto, la sustitución del capital ismo por un nuevo sistema; temas éstos que, por su envergadura, no nos correspondediscurrir. Lo quees un hecho innegableesla permanencia efectiva delas fronteras naturales. Éstas se encuentran, en la actualidad, en el límite de carga de los ecosistemas marinos y terrestres, en la debilitada capa de ozono, en la reforestación, en el saneamiento delas áreas perturbadas, en la lucha contra la contaminación atmosférica, hidrológica, subterránea y terrestre. Así, las nuevas fronteras naturales tienen una doble identidad: la reparación de daños al ambiente y la prevención delosmismos.

Es importante notar que esta reconfiguración de los límites naturales no sólo se impone al desarrollo de la sociedad, sino a la continuidad dela vida en esteplaneta. Las nuevas fronteras naturales no son propias de una región, de un país, de un grupo social en particular, sus efectos gl obal es involucran y afectan a tod os los hombres, mujeres y niños en general, donde sea que habiten y cual quiera que sea su ocupación.

Siendo el papel de la historia el de analizar las causas que nos condujeron a la situación presente y [...] a la vista de la gravedad de la crisis ambiental, se deberían cuestionar los supuestos teóricos y metodológicos con los que hasta ahora hemos abordado el pasado. El replanteamiento crítico debe partir de una nueva teoría en la que se restituya la unidad entrelos seres humanos y la naturaleza. A esta tarea se dedica la historia ecológica (González de M olina y Martínez, 1993).

Por lo tanto, es una necesidad insoslayable incorporar el enfoque ecohistórico en el análisis histórico de la frontera como una nueva concepción cultural. 
Baja California es una de las penínsulas más largas del mundo, con aproximadamente $1300 \mathrm{~km}$ delongitud y una anchura máxima de 240 km (Wiggins, 1980:125). Seencuentra casi rodeada por mar, al estepor el golfo deCal ifornia y al oeste por el océano Paćfico, situación que le confiere una calidad casi insular y que origina una de sus principales constantes geohistóricas: el aislamiento.

A lo largo dela península se erige un complejo montañoso formado por elevadas serranías. En la mayoría de éstas, la pendientedel golfo es más pronunciada que la del Pacífico, y se encuentran cortadas transversal o diagonalmentepor numerosasfallas. En el extremo noroeste dela mitad de la península se encuentra el desierto del Vizcaíno, que esuna planicieárida y extensa. Otro aspecto particular dela fisiografía peninsular es la presencia denumerosas islasen ambas costas, con muy variadas características todas ellas (Breceda y Cariño, 1995:13-28).

La aridez es una de las principales características de la geografía sudcal iforniana, sin embargo, existen correntías que hacen posible la vida en este territorio. El drenaje natural de Baja California (Wiggins, 1980:23) consiste en numerosos arroyos casi rectos que forman profundos cañones. Casi todos los arroyosseencuentran secos la mayor partedel año, por el lo la principal fuenteson los acuíferos subterráneos.

El clima dela península es cal ientey seco, en gran partedeterminado por su posición latitudinal. Las temperaturas de verano son más al tas en el noreste, y pueden llegar por arriba de los $43^{\circ} \mathrm{C}$ hasta $50^{\circ} \mathrm{C}$. La costa del golfo es más cálida que la del Pacífico a la misma latitud. La precipitación anual es más al ta en las montañas y mucho menor en las laderas desérticas. Dos diferentes patrones de lluvias se presentan en Baja California. En general, de la mitad norte a dos terceras partes de la península reciben la mayor cantidad de precipitación durante los meses de invierno. En la porción sur, la mayor cantidad de lluvia se presenta durante el verano, y generalmente bajo forma torrencial. A pesar dela existencia deestos patrones deprecipitación, Baja California forma partedel gran desierto sonorense, quetiene un promedio anual de lluvias menor a $200 \mathrm{~mm}$, y en ciertas áreas llega apenas a $50 \mathrm{~mm}$ (Breceda y Cariño, 1995:38). 
En cuanto a la flora de Baja California, se han reportado 2958 especies y subespecies de plantas (Wigging, 1980). Es característico de su vegetación la poca riqueza específica de las familias vegetales que en ella seencuentran, y las que presentan mayor variedad de especies son: compuestas, gramíneas, leguminosas y cactáceas. En general, la vegetación de la región presenta la fisonomía de un desierto arbóreoarbustivo.

Por otra parte, la fauna dela península se distribuyeen una amplia gama de grupos de animales terrestres (mamíferos, aves, reptiles y, sobretodo, insectos) aunque la fauna marina es mucho más variada y abundante.

Las características geográficas queacabamos deesbozar, evidencian la hostilidad del entorno bajacaliforniano para el establecimiento y desarrollo dela población en general, y particularmente dela sociedad occidental. Sólo los indios californios lograron, tras largos siglos de experiencia, y probablemente ante la imposibilidad de migrar hacia regiones más benignas, adaptarsesimbióticamenteal medio geográfico peninsular. Esta adaptación estaba basada en las siguientes estrategias: una gran economía energética, un uso variado e integral de la diversidad biótica, y el respeto a los niveles de carga de los ecosistemas de los que extraían su sustento (Cariño, 1996b:47-49).

Fueron necesarias más de diecisiete décadas para que en Baja Californiainiciara el proceso deanexión definitiva al imperio español. $\mathrm{Ni}$ el ímpetu expansionista de los conquistadores y colonos españoles logró vencer tanto el aislamiento como la aridez; esta hazaña se debe al celo misional de los jesuitas que creyeron poder establecer en esta tierra, pobre y al ejada, un reino mariano. Paradójicamente, la ruptura delasimbiosishombre/ natural eza delos californios al ser parcialmente incorporados al sistema misional, redundó en el fracaso de la utopía jesuita. Antes de poder hacer a los cal ifornios cristianos ejemplares, la inadecuación de la tierra y los aborígenes peninsulares a los medios civilizatorios occidentales, conllevaron a una mortalidad masiva que dejó a las misiones sin neófitos.

Baja California pudo tener una historia contemporánea a través del mestizaje cultural de los rancheros sudcalifornianos con el que diseñaron inteligentes estrategias de adaptación al ambiente. La 
economía y la cultura ranchera remiten a una civilización material sui generis, en la que se complementaron las estrategias de adaptación de los ignacianos y el conocimiento indígena del potencial natural. En este caso, el aislamiento y la aridez no fueron obstáculos al desarrollo ranchero, por el contrario, dieron origen a una identidad cultural a la que hoy seleconfiere un papel pionero.

En el siglo XIX, Baja California entró a la era de la globalización a través del saqueo de sus recursos naturales, como será comentado en el último apartado de este capítulo. Para explicar la historia regional de los siglos XIX y XX, el modelo de la Raubwirtschaft es idóneo. Los intereses del mercado mundial, la debilidad del Estado mexicano, la escasa población bajacaliforniana y la riqueza del potencial natural peninsular, constituyeron una coyuntura en la que las fronteras naturales se diluyeron eincluso se extinguieron antelos recursos dela explotación capitalista.

La estratégica ubicación dela península, con su vasto frenteoceánico y su cercanía a la California estadounidense, como en los tiempos del comercio de la nao de China, recupera su importancia en el concierto internacional y en particular en el de la cuenca del Pacífico. Por citar un ejemplo, durante el siglo XIX, en espera de la integración de la península al territorio estadounidense, la árida tierra que había sido un obstáculo al desarrollo, se convirtió en un peleado recurso para la especulación de bienes raíces.

Las distintas percepciones - tanto entre mexicanos y estadounidenses-del espacio bajacal iforniano evidencian quelo que paraunos era una frontera natural que presentaba obstáculos infranqueables para el desarrollo productivo, para otros era una frontera muy atractiva para la expansión económica, eincluso, para algunos, política también.

Así, Baja California, para el gobierno federal decimonónico, fue el territorio prescindible, el comodín en las negociaciones diplomáticas con el país vecino.

En cambio para éste, la península fue (y sigue siendo) una región codiciada por sus recursos naturales y por su ubicación geoestratégica, aspectos éstos que serán discutidos más detenidamenteen el siguiente apartado. 
Baja California, que tiene un medio geográfico inestable y frágil, cuyos recursos renovables han sido víctimas dela Raubwirtschaft, en la actualidad no ha podido aún beneficiarse de un reencuentro con la identidad geográfica demostrada por indiosy rancheros. Más bien sigue sometida a los efectos perversos de la racionalidad del mercado internacional y dela debilidad eignorancia del gobierno mexicano. El saqueo de los recursos naturales y humanos son una realidad que no pueden disimular los cínicos discursos del desarrollo sustentable. Hay débiles - aunquesignificativas - voces quedenuncian la usurpación de las costas por el capital extranjero y la consecuente destrucción del paisaje-quees un recurso natural no renovable-, el uso abusivo del suelo, el agua y los hombres en los campos concesionados a la agricultura intensiva transnacional, la contaminación por desechos sólidos, líquidos y gaseosos, etcétera, pero aún no seha emprendido la batal la para lidiar con las nuevas fronteras naturales y aprender así a vivir en un sistema demenor desigualdad social y demayor respeto al ambiente.

Desde el siglo pasado, el aislamiento y la aridez dejaron de ser, en cierta forma, barreras quehicieran deBaja California unaregión refugio capaz demantenerseal margen delos efectos perversos dela expansión capitalista. No obstante, es importante señalar que siguen siendo obstáculos parala integración nacional dela región, aún son espejismos que al ejan al tibio capital nacional, y continúan siendo pretexto a la ineptitud delos gobernantes. Cierto esqueel mar y el desierto confieren a la península una cualidad prácticamente insular, aunque en la actualidad, con los medios de comunicación y de transporte que caracterizan a la globalización, estos obstácul os naturales no guardan, ni por asomo, la misma significación queen años anteriores.

Es tiempo ya dequese entiendan en su real y actual dimensión las características geográficas bajacalifornianas, y esto en beneficio, primero, de sus moradores, y luego de los otros mexicanos. El paradigma de la vieja frontera natural es obsoleto y nefasto para el desarrollo sustentable de la región. La cabal comprensión del paradigma delas nuevas fronteras naturales puedeabrir la brecha para que en Baja California Sur dicho modelo de desarrollo deje de ser demagogia y logre realizarse de manera efectiva. 
Identidad es una palabra de difícil definición. En el diccionario se le consigna como la correspondencia de una cosa consigo misma. En el uso común, comprobar la identidad de al guien es constatar que ese alguien es quien dice ser. En el caso de la identidad de cualquier congregación humana se da una serie de características comunes que identifican a sus miembros como pertenecientes a ese grupo. Estas características les permiten identificarse entresí como parte de al go y les permitediferenciarse deotros grupos humanos. La identidad no es algo tangible ni conmensurable. La identidad es un fenómeno netamentehumano y seforma a través de una coyuntura histórica, económica, social, educativa y geográfica. Todos los componentes materiales y culturales que intervienen en la vida de una sociedad son factores que inciden en la formación de su identidad. La identidad tampoco es inamovible, está en constante cambio, y éste es de larga duración (Braudel, 1989), ya quela mentalidad, y sobretodo la colectiva, aunque setransforma, lo hace de manera lenta.

La identidad no es al go tangible, sin embargo, es posible aprehenderla mediante las manifestaciones culturales, entendiendo por éstas todo lo que es obra y acción del hombre, en oposición a la naturaleza, quees al go dado, no elaborado, no cultivado (D iccionario Enciclopédico A rgos V ergara, 1977). Llamemos entonces a la identidad de un grupo humano, identidad cultural.

Los grupos humanos son más conscientes desu identidad cultural - la reafirman- cuando interactúan con grupos humanos con identidad cultural distinta. La existencia del otro marcalas diferencias que permiten saber lo queno sees $y$, al mismo tiempo, conocer y analizar las características quelehacen distinto. Sin embargo, la identidad también se vive por similitud, los miembros del grupo se identifican con sussímiles, por lo tanto, la identidad semanifiesta entre congéneres.

Así, toda agrupación forma, poco a poco, su identidad a través de cierto consenso, por lo cual se le advierte en todas las actividades colectivas, reflejo a su vez de las actividades individuales que la 
retroalimentan. De esta forma, la comunidad genera una serie de costumbres, de tradiciones, una vida cultural (literaria, artística, etcétera) común. En la investigación histórica el análisis dela identidad cultural es sumamente importante, pues es un componente fundamental dela historia social , la historia cultural , la historia de las ideas, la historia de las mentalidades, en suma, trasciendeen el estudio dela conducta colectiva.

Sepuedenotar lo difícil queresultallegar a un concepto deidentidad cultural, pero el problema se complica cuando tomamos en cuenta la existencia deidentidades cultural es insertas unas en otras. Los niveles deidentidad cultural forman un modelo deinterrelaciones a semejanza de las matruscas rusas. Una comunidad forma su identidad cultural por influencias que provienen de varias magnitudes espaciotemporales. De la misma manera, varios grupos humanos con una identidad cultural propia se unen y forman entre todos una organización humana más compleja, quetendrátambién una identidad cultural propia. Esta nueva identidad cultural buscará elementos comunes entre estos pequeños grupos para formar una identidad cultural común, pero en ningún momento significará la desaparición de las particularidades de cada uno de esos grupos. Así tenemos que laidentidad cultural deun área geográfica devastas dimensiones-América Latina, Europa occidental, por ejemplo- guarda relación con las identidades culturales que la conforman, en un proceso de constante retroalimentación. Por lo tanto, no es lo mismo la identidad cultural de determinado barrio de La Paz, que la de la ciudad de La Paz, que la sudcaliforniana, quela del nortedeM éxico, quela mexicana, ni quela latinoamericana, aunque al mismo tiempo un paceño sea sudcaliforniano, norteño, mexicano y latinoamericano.

A hora bien, la identidad cultural funciona en dos sentidos: como unificadora y como diferenciadora. En su función unificadora permite quecualquier agrupación humana atelazos. En su papel diversificador, la identidad cultural forma fronteras entre las distintas agrupaciones humanas. La identidad cultural se reafirma antela igual dad y ante lo diverso. Un pueblo define y redefine su identidad a través de actividades y actitudes colectivas y también al enfrentarsea identidades culturales distintas. De hecho no es fácil transformar la identidad de 
un pueblo o asimilar costumbres diferentes. Uno delosfactores quemás inciden en la modificación de cierta identidad son los contactos interculturales. Los procesos de aculturación, además de ser lentos y largos, pueden ser traumáticos, violentos y destructivos, antes de dar origen al surgimiento deuna cultura. Aunqueclaro, las congregaciones humanas no sólo no están exentas de entablar relaciones con otras congregaciones, sino que les es imposible dejar de influir y recibir influencias. Así, el contacto paáfico y las relaciones comercialesmotivadas por la vecindad en los tiempos antiguos y por la globalización en los actuales, han sido factores que han permitido los contactos culturales y sus respectivas influencias. Sin embargo, estos contactos intercultural es se dan en diferentes grados y de diferentes maneras.

El fenómeno deaculturación ha estado presente a lo largo de toda la historiadel hombre. Hasta el siglo XIX Ias conquistas fueron un motor decambio, deadaptación, derenovación y dedesaparición dediversas culturas. En la forma de conquista y en la actual de subordinación económica, la identidad se ha manifestado como un importante elemento dedominación, y en menor medida, deresistencia. Los países imperialistas necesitan mercados, mano de obray afirmar su identidad ante los países subordinados. El mundo es cada vez más pequeño gracias a los avances científicosy a los medios de comunicación, por lo tanto, es cada vez mayor el contacto entre diferentes identidades culturales, tanto cual itativa como cuantitativamente.

La modificación consciente de la identidad de cualquier pueblo puedeconvertirseen un arma muy peligrosa, si sepiensa quela riqueza cultural podría ser dirigida de tal forma que se subordinase ésta al interés económico. No obstante, la identidad cultural es al go muy fuerte, la única manera de desaparecerla es eliminando a todos sus componentes, lo que ha sucedido en contadas y lamentables ocasiones.

Los puntos de mayor contacto cultural y, por lo tanto de mayor variación, choque y retroalimentación de identidades culturales, son las zonas fronterizas. Éstas, como todos los espacios geográficos, al mismo tiempo que separan, unen. 
Como se ha señalado, desdeel siglo XIX uno de los problemas que enfrentó el gobierno federal mexicano fuela integración delos estados norteños, al ejadosfísica y cultural mentedel centro político y económico de la república. Estos estados tuvieron que vivir el abandono y la incomprensión del gobierno federal. La política de la época no supo considerar la especificidad cultural de esos territorios, pues aunque formaban partede México, no tenían la misma dinámica política, social y económica. Por ello, desdeentonces sedictaron políticas inadecuadas a la real idad fronteriza, con el consabido costo territorial y económico.

Baja California Sur es un estado perteneciente a México que, sin compartir territorio con la línea divisoria internacional, funge como frontera con Estados Unidos. Esta característica de pseudofrontera afecta determinantemente la identidad cultural sudcaliforniana. La incomprensión de esta situación sui generis, así como la falta de conocimiento de las potencialidades naturales calisureñas por parte del poder central, han provocado que a Baja California siempre se le haya tratado como la parte prescindible dela federación, aquélla que cada vez que ha sido necesario, se ha puesto en la mesa de negociaciones, buscando cederla o venderla a Estados Unidos. Curiosamente, sólo el rechazo de estas ofertas por parte del senado estadounidense, ha sal vado de la anexión a la península.

Las condiciones geográficas de aislamiento y aridez no han permitido que la población sudcal iforniana sea muy numerosa. ${ }^{8} \mathrm{~A}$ lo largo de toda su historia, Baja California se ha nutrido de población quellega demuy diversos lugares, tanto del extranjero como devarios estados de la república. Franceses, ingleses, estadounidenses, sinal oenses, sonorenses, guerrerenses, entremuchos otros, han formado el pueblo sudcaliforniano, por lo tanto, podría pensarse que es una gran mezcla, tal vez uniforme, de todas estas influencias culturales,

\footnotetext{
${ }^{8}$ A rchivo Histórico del Estado deBaja California Sur. "Pablo L. Martínez" (AHPLM), vols. 234, 244, 323, 400, 785, 866, Archivo General de la Nación (AGN), A nuario estadístico de la Secretaría de Fomento, Colonización, Industria y Comercio, 1892, 1894, 1895, 1897, 1898.
} 
pero no es así. Baja California Sur tiene características culturales bien definidas y su gente es partícipe de una identidad sui generis. No negamos que la gente llega y trae consigo sus tradiciones, pero las condiciones devida en la península son tan extremosas, quees más lo que esta población foránea tiene que hacer para adaptarse que lo que puedeinfluir en las costumbres locales. Sin embargo, no podemos negar que, ante tan nutridos contactos, los sudcal ifornianos han creado una identidad flexible, abierta, quesólo así ha podido sobrevivir anteestos embates culturales; esto la convierteen una identidad cultural con raíces muy estables y muy fuertes.

Por otra parte, la sociedad sudcal iforniana está compuesta por varios grupos sociales que coexisten y, eventualmente, se enriquecen mutuamente. Por un lado, tenemosala población quepodríamos llamar autóctona, formada por los primeros col onos civiles quellegaron en el siglo XVIII y queforjaron la cultura ranchera. Ésta es considerada como la identidad sudcaliforniana primigenia. Los rancheros pudieron sobrevivir en el medio sudcaliforniano con una mínima dependencia del México continental y mucho menor de Estados Unidos. Los rancheros crearon una cultura de autosuficiencia. Vivían en una situación precaria y sabían lo importante que era para sobrevivir el aprovechamiento integral y racional delos recursos naturales (Cariño, 1996b:65-103). Ésta es la cultura que se encargó de conservar el conocimiento de la herbolaria de los indios californios, que sabe aprovechar la flora y la fauna silvestres, que gusta de inventar historias extraordinarias sobreanimales extraordinarios; esuna cultura quevive inmersa en la mística del desierto y la serranía.

Debe quedar claro que estos rancheros no tienen nada que ver con los hacendados o terratenientes del M éxico continental . La geografía sudcaliforniana nunca ha permitido la existencia de haciendas y latifundios de aquellas dimensiones. ${ }^{9}$ Ésta es una característica muy

${ }^{9}$ AGN, M emoria de la Secretaría de Fomento, Colonización, Industria y Comercio, 1868, 1870, 1883, 1894, 1898, AGN , M emoria deH acienda y Crédito Público, 1863-1864, AHPLM, Boletín oficial, 1881, vol. 164, exp. 4. 
importante en la formación de la identidad sudcaliforniana y que contrasta profundamentecon la identidad nacional. No se debeolvidar quela unificación de México, su consolidación como país, se da sobre las bases de una revolución que encontró su principal sustento en la abolición de numerosas injusticias que se vivían en el agro mexicano. En Baja Cal ifornia Sur, el peonajeacasillado, por citar sólo un ejemplo, erainexistente. La problemática sudcal iforniana era muy distinta dela quese vivía en el centro del país.

Lacultura delosrancheros, hoy casi desaparecida, seha manifestado en diferentes formas según han cambiado las condiciones económicas y políticas sudcalifornianas. Parcialmente permaneceen ranchosaislados, otra parte se conserva en los pueblos que, por no ser tan importantes para el capital internacional, sehan mantenido como oasis culturales.

En el siglo XIX, con el augedeactividades como el buceo de concha perla, la minería, la explotación de diversos productos pesqueros y la extracción desal, seconsolidó una población porteña queforjó su propia identidad cultural. Estas personas estuvieron mucho más ligadas a los grandes empresarios y capitales extranjeros en comparación con los rancheros. Los paceños vivieron el saqueo de los recursos naturales sudcal ifornianos de manera más cercana, e incluso participaron en él con su fuerza detrabajo. Esta población, a diferencia dela ranchera, es una población urbana, queaunquefueinfluida por algunas tradiciones rancheras, tiene una identidad cultural propia que se basó en una economía orientadaal exterior. En esteúltimo punto los porteños y los rancheros fueron diametral menteopuestos.

Entre los porteños, los grandes comerciantes y empresarios de mentalidad burguesa se destacaron por su preeminencia económica desde mediados del siglo XIX. Fue este grupo el que estableció los vínculos con el mercado internacional, y también el que empleó en su conveniencia - y en la medida de sus posibilidades- las políticas centrales mexicanas. Este grupo tiene también su propia identidad cultural, distinta a la de los rancheros y los porteños, pero con influencias deambas.

Es posible distinguir otro grupo formado por algunos de los herederos de la cultura ranchera que vivían en los pueblos sureños y que en el siglo XX migraron a la capital (La Paz). Los que tuvieron 
mayor suertelograron realizar estudioseinclusiveestudios superiores en la ciudad deM éxico. Esta generación desudcal ifornianos con mayor preparación hasido la que ha concientizado y defendido más la esencia de la identidad cultural sudcaliforniana en las zonas urbanas en las últimas décadas. Sin duda, al pasar cierto tiempo fuera desu terruño y tener la oportunidad de confrontar su identidad con la de otros mexicanos, reconocieron y valoraron los rasgosoriginales desu cultura. Desgraciadamentesus sucesores han ido perdiendo esa esencia y hoy vivimos precisamente un momento en el quetanto la conciencia como la val orización de esa identidad, parece perderse.

Finalmente en sudcalifornia, desde los años sesenta se han engrosado las filas de otros dos grupos que habitan la entidad pero quetienen una identidad cultural distinta. Setrata deinmigrantes del macizo continental mexicano y deN orteamérica. El grupo demigrantes mexicanos evidentemente dista mucho de ser un grupo homogéneo, pero se pueden diferenciar los extremos: intelectuales y jornaleros agrícolas. Por otra parte, el grupo de los migrantes estadounidenses son en general jubilados queaprecian las bondades dela estación "fría" de Baja California Sur. Por su proporción, posición social, poder económico eimportancia en el mercado de trabajo, los migrantes, con sus muy variadas identidades culturales, han influido, influyen e influirán aún más en la identidad cultural sudcaliforniana. Éste es un campo fértil y virgen parala investigación antropológica, y en realidad los efectos aún no han sido evaluados en lo más mínimo.

Sea como fuere, en sudcal ifornia aún resulta evidente, ante los ojos de todo visitante sensible y curioso, que éste es "Otro México". Por cierto, nuncasuficientementeval orado ni conocido por los compatriotas, y siempreanhelado por los extranjeros.

\section{LASFRONTERASECONÓMICAS: INTEGRACIÓN Y DESINTEGRACIÓN DE MERCADOS}

NOTAS CONCEPTUALES

Robert Pastor (1995:264-281) analiza el reordenamiento de las viejas y lasnuevas fronteras económicas deM éxico. La vieja frontera, la frontera nacional de raíz decimonónica, tuvo razones internas y externas. Las 
razones internas eran la pérdida deterritorio, una frontera demás de $3000 \mathrm{~km}$ con una superpotencia, la posibilidad de que México fuera rebasado por un país con menor cultura y el temor a un avasallamiento económico y cultural. La vieja frontera justificaba la protección de hombres denegocios antela competenciay el mantenimiento deun grupo político en el poder. Lospilares deestavieja fronterafueron: 1) unamística revolucionaria de defensa de valores patrios; 2) una política exterior antiestadounidense; 3) una estrategia económica productiva limitada pero funcional de 1940 a 1982, y 4) un sistema de partido dominante. Con estos pilares cumplía funciones paradigmáticas para los países con problemas similares y permitía cierta hegemonía en la región. El nacionalismo dela vieja frontera es, para Pastor, uno defensivo.

A esta frontera se contrapone la que puede llamarse "nueva frontera". Pastor entiende quea partir del gobierno de Carlos Salinas, México real izó renegociación delas fronteras económicas. Las premisas de esta situación están en el fin de la guerra fría, la constitución de los bloques europeos y asiáticos, y la necesidad delos Estados Unidos de competir con Japón y Europa aprovechando la fuerza de trabajo mexicana barata. Las medidas del gobierno salinista provocaron la apertura dela economía nacional y ladelosmercados latinoamericanos. En la práctica abrió el mercado nacional al mercado estadounidensey propuso un acuerdo delibre comercio nadando a contracorrientedela tradición política y económica latinoamericana que México había iniciado para garantizar un funcionamiento administrativo acordecon su mercado nacional y su política internacional.

Para Robert Pastor, la nueva frontera económica no hace más que abrir la economía mexicana a los Estados Unidos, y tiene como fin un régimen hemisférico delibre comercio. El resultado esperado será una mejor capacidad para competir en el mercado de los bloques.

Por otra parte, para explicar la conformación demercados y fronteras económicas, Carol Smith (1991:40) proponeel uso demodelos espacioregionales de sistemas económicos específicos a partir de cinco elementos: 1) regiones, 2) sistemas deintercambio, 3) lugares centrales, 4) niveles sistémicos y 5) relaciones de ubicación.

Los sistemas de intercambio se forman por relaciones económicas entrecomunidadeso asentamientos en un territorio, y seinterrelacionan 
entresí por una red o arreglo jerárquico con un lugar central quefunge como eje de un sistema jerárquico queagrupa a otros asentamientos o comunidades donde se concentran las mercancías, la gente y la información. A su vez, se crean sistemas regionales complejos que incluyen más de un lugar central constituyendo un nodo de sistemas incluidos. Estos lugares centrales se relacionan por un sistema de relación de ubicación entre ellos y sus periferias, de forma tal que proveen un marco metodológico en el que los sistemas regionales y sus niveles sistémicos se relacionan, describen y delimitan. De esta manera, los sistemas de intercambio y los lugares centrales determinan la integración regional de la economía (Smith, 1991:42), es decir, conforman fronteras económicas.

Las condiciones del mercado, el transporte y las características administrativas establecen jerarquías en cuanto a lugares centrales, y el crecimiento crea irregularidades que definen la dinámica misma del mercado y la economía desarrollando diversos sistemas dedistribución (Smith, 1991:66): 1) solar, 2) reticular y 3) dendrítico. El sistema solar es controlado por un centro político-administrativo, y es ideado para la administración política y territorial. El sistema dendrítico concentra en un solo lugar central de más alto nivel a los centros de más bajo nivel quele son tributarios y donde no hay comercio horizontal entre distintos productores. El sistema reticular se basa en la autosuficiencia, se da el intercambio local y sirve para adquirir dinero para la compra deartículos deprimera necesidad.

A su vez, Immanuel Wallerstein (1974), señala que el sistema capitalista está compuesto por tres partes: un núcleo desarrollado en Europa occidental, una semi periferia desarrollada en el sur y este de Europa, y una periferia subdesarrollada en la mayor partedel mundo. Con estas tres partes, Wallerstein argumenta "que la dinámica del capitalismo está basada en el desequilibrio estructural creado por las economías regional es queintegran un sistema mundial que permitela concentración del capital en una parte de él" (Wallerstein, 1974:90). "El grado en el que este desequilibrio tiende a la permanencia, el subdesarrollo se desarrolla junto con el desarrollo para convertirseen ajuste económico relativamente estable". Este fenómeno ayuda a entender el equilibrio que brindan, con su subdesarrollo, las regiones 
periféricas a las economías que complementan. “Las áreas periféricas proporcionan materias primas, mano de obra o mercados que parecen consolidar el desarrollo de las áreas nucleares". Por último, establece que “ningún subsistema deuna economía puedeentenderseaislándolo delos otros subsistemasy, además, ninguna economía nacional puede entenderse sin entender la relación entre sus subsistemas regional es" (Wallerstein, 1974:95).

Interesa ver esto en términos más amplios. Darcy Ribeiro (1978) argumenta que la evolución sociocultural se basa en una serie de revoluciones tecnológicas generadoras de múltiples procesos civilizatorios que dan nacimiento a diversas formaciones económicosociales o socioculturales, y provocan focos dinámicos de pueblos activados por el dominio de las nuevas técnicas y tecnologías. Los focos se difunden por áreas contiguas o distantes constituyendo imperios. Todos los pueblos se transforman a través de una autoconstrucción y modernización dependiente con la primacía de quienes dominan el proceso civilizatorio o centro rector. Para quien es alcanzado por el proceso civilizatorio, éste es un movimiento de actualización o incorporación histórica que los coloca bajo el dominio de un centro rector (una especie delugar central de la revolución tecnológica y del proceso civilizatorio), haciéndolo transitar también de una a otra etapa evolutiva, pero con pérdida de su autonomía y mediante su conversión en proletariado externo de otros pueblos. Es decir, como proveedores defuerza detrabajo o deproductos destinados a promover la prosperidad ajena (Ribeiro, 1978:21).

En términos más actual es y en palabras deH éctor Cuadra (1997), el traslado demodel os cul turales y económicos (la actualización histórica de la que habla Ribeiro) es la globalización. En este proceso las transacciones económicas se hacen por medios el ectrónicos quehacen perder sentido a las fronteras políticas, provocando una desterritorialización dela actividad económica. Entonces, si a cadamercado nacional correspondía un Estado nacional, las actividades económicas y su manejo a distancia disminuyen la operatividad jurídica y política de losEstados superando la territorialidad delosmercados en las fronteras físicas. Cuadra añade, de acuerdo con Octavio Lanni, quela sociedad moderna internacional actúa a través de un mercado, finanzas y una 
política global, y con Wallerstein, que existe una tercera división internacional del trabajo que se orienta hacia la desterritorialización de las etapas de la producción en serie de las mercancías que abarata el proceso económico, integrándose así las economías nacionales a la economía mundial.

Tenemos, entonces, que los lugares centrales articulan mercados organizando sistemas de intercambio dentro de ese mercado y asignando funciones a partir de las relaciones de ubicación al funcionamiento del mercado y sus partes. Estas partes organizan su sistema dedistribución demanera solar (en el caso dela administración territorial), dendrítico (en el caso deeconomías quecomplementan otras economías de centro rector) y reticular (en el caso de economías de subsistencia). Las regiones tienen su centro y su periferia integrada con funciones determinadas por la división nacional y/ o internacional del trabajo, donde el subdesarrollo de una región opera como factor que equilibra y concentra el desarrollo en los lugares centrales. Con esta descripción general sepuedeentender la situación delas fronteras económicas de un mercado.

Si estos elementos teóricos sobre la estructuración de los mercados los relacionamos con los planteamientos de Ri beiro, podemos ver cómo estas estructuras y relaciones en la conformación de los mercados que defineSmith, están, a su vez, relacionadas con los procesos civilizatorios que generan las revoluciones tecnológicas a las que hace alusión Ribeiro. La actualización histórica incorporará, modificará o determinará las funciones delas regiones, el lugar o los lugares centrales y los sistemas regionales complejos, y con ello, establecerá fronteras económicas e incorporará territorios a su mercado. Esto nos permite entender tanto los procesos de incorporación al mercado nacional y la conformación delas regiones económicas internas - los subsistemascomo los procesos derelaciones económicas internacionales. Y si en el pasado esto fue llamado colonialismo o neocolonial ismo, las nuevas revoluciones tecnológicas y los nuevos procesos civilizatorios tienen ahora por nombreglobal ización. Sehan conformado nuevos mercados y bloques económicos con tres características señaladas por Héctor Cuadra: a) pérdida desoberanía, b) pérdida deautonomía económica, y c) presiones sobre las atribuciones del Estado. 
Con estos elementos teóricos podemos aproximarnos a la historia de Baja California Sur y tratar de entender algunos aspectos de su incorporación a las fronteras políticas y económicas del Estado mexicano y a las fronteras económicas del mercado mundial a través de la explotación de sus recursos natural es y la agricultura.

Miguel León-Portilla (1994:26) se refiere a la California peninsular mexicana, y destaca su importancia durante el periodo colonial para garantizar el dominio del Pacífico, facilitar una ruta de las especies, acceder al buscado paso transoceánico del norte, y apoyar la expansión hispánica en Asia, así como el tornaviaje dela nao deChina. Por estos motivos, desdeel siglo XVI seintentó la incorporación deCaliforniaal mercado global español.

A pesar delos esfuerzos hispánicos y novohispánicos, fue hasta el sigloXIX queBaja California seincorporó a los circuitos dela economía mundial. Este siglo también marcó demanera particular la vida dela península evidenciando la vulnerabilidad de la línea divisoria internacional en el territorio cal iforniano. La guerra contra los Estados Unidos y la amenaza constante de su anexión a ese país son ejemplos de esa debilidad. Ésta, en buena medida era producto de su escasa población, desu débil incorporación al mercado nacional y desu papel en la distribución internacional del trabajo en tanto quezona periférica delos mercadosmás importantes: Estados Unidos, Francia el nglaterra.

La explotación de los recursos naturales sudcalifornianos bajo el modelo de saqueo ${ }^{10}$ fue la manera decimonónica en la que Baja Californiaseincorporó al mercado mundial. El impacto deesta inserción en el desarrollo del territorio fue marginal, como también lo fue su integración al mercado nacional. Sudcalifornia fue la periferia subdesarrollada queentregó recursos naturales a través de un sistema dedistribución dendrítico.

${ }^{10}$ Modelo en el quepredomina la racionalidad del mercado, la sobreexplotación de la riqueza natural y la ausencia de acumulación local de capital. (Ver M. Cariño, 1996b). 
Las ostras perleras fueron el primer recurso saqueado. A unque la pesca de perlas estuvo relacionada con la demarcación y la conquista de Baja California desde el siglo XVI, fue hasta el siglo XIX que la explotación de las ostras perleras se llevó a cabo a mediana y a gran escala. El nácar y las perlas del golfo de California entraron como mercancía privilegiadaal mercado mundial por la vía francesa a través deParís, pero también por Nueva York y Hamburgo (Cariño, 1996a:32). A partir dela introducción dela escafandra, las compañías extranjeras obtuvieron concesiones exclusivas de vastas zonas marítimas. Tras la liberación de la pesca de ostras perleras, con la rescisión del contrato deconcesión dela compañía inglesa TheM angara Exploration Co. Ltd., en 1912, los armadores locales contaron con menor capital y dispusieron de un recurso mermado. A causa del agotamiento, la explotación perlífera colapsó en 1940.

También se sobreexplotó la bal lena gris en la primera mitad del siglo XIX. El gobierno no recibió pago al guno por el saqueo del recurso, y ni siquiera hubo capacidad para proteger ni litigar en su defensa. En 28 años se pescaron 10800 ballenas llegando casi a su extinción. Durante el siglo XX, la actividad pesquera seorientó a peces como el tiburón, el atún y otras especies comestibles siempre con destino al mercado internacional y con características al tamente depredatorias.

Otras actividades económicas como la minería también beneficiaron a compañías extranjeras. El oro y la plata quese habían explotado desde la colonia, formaron, en el siglo XIX, una red comercial y política interesando los establecimientos de Todos Santos, La Paz, San A ntonio y El Triunfo. Ya entre 1880 y 1910 la minería era coto casi exclusivo de extranjeros. Por ello, la economía local dependía para vivir del mercado mundial y generaba presión al gobierno federal. El ejemplo más importanteen materia deminería es el dela compañía minera El Boleo en Santa Rosalía, que además de tener grandes ventajas del gobierno, no pagaba impuestos, a pesar de haber sido una de las compañías mineras más importantes del país (Cariño, 1996b:167).

El saqueo de la orchilla por compañías colonizadoras se basó en concesiones territoriales. Dichas compañías, además de no pagar impuestos y hacer contrabando, nunca cumplieron con suscompromisos poblacionales. Podemos inferir que, "además de la extracción de los 
recursos naturales, el principal objetivo de los concesionarios era la especulación fincada en la expectativa dequela península fuera anexada total o parcialmente por los Estados Unidos" (Cariño, 1996a:47).

El gobierno federal tenía grandes esperanzas en los logros de las compañías extranjeras que recibieron vastas concesiones territoriales en BajaCalifornia (cerca de $90 \%$ dela superficiepeninsular). Seesperaba una establey productiva colonización, el establecimiento de una base técnica-material, apoyo al transporte de cabotaje y a la comunicación en general. Así, a cambio de las ventajas que se les concedieron, se apostó por la incorporación del Territorio al mercado y la frontera política nacional, y a la incorporación histórica dela que habla Ribeiro, teniendo por meta el desarrol lo económico regional. Pero en muy pocas ocasiones las compañías extranjeras cumplieron con esas funciones. Lejos de provocar el desarrollo esperado por el gobierno federal, incorporaron los recursos naturales, el espacio geográfico y la población regional a las redes de los mercados capital istas central es sin que las fronteras nacionales cumplieran su cometido, a saber: regular el uso de los recursos, garantizar la incorporación del Territorio a la vida nacional y mejorar la economía regional en forma amplia.

Volviendo la vista al proceso histórico, de los siglos XVI al XVIII destacan los intentos de incorporación de Baja California a las redes económicas, políticas y comerciales delos lugares centrales dela Nueva España y, al mismo tiempo, su inserción en el sistema de comercio intercontinental. Estos esfuerzos no dieron resultado, por lo que puede deducirsequelas redes dedistribución debieron ser del tipo reticular, para la población civil, y de tipo solar, desde la estructura política, administrativa y religiosa. Se infiere que la economía informal y el contrabando complementaron el sistema reticular de la economía, y acercaron la región a la economía mundial ante las dificultades novohispanas de cumplir con la función de lugar central en esos procesos civilizatorios -en términos de Ribeiro.

Fue hasta el siglo XIX cuando las fronteras políticas y económicas sevolvieron más efectivas. La península fue incorporada a los procesos civilizatorios de los centros rectores europeos a través de una división nacional einternacional del trabajo, en la queM éxico asignó a la región la función deabastecedora derecursos naturalesala industriamundial, 
sin poder resolver su incorporación efectiva a las fronteras económicas y políticas nacionales. Esta función de periferia subdesarrollada delos lugares central es se expresa ya a través de las negociaciones políticas (Tratado McLane-Ocampo, por ejemplo) y las distintas concesiones territoriales a compañías extranjeras (Castañeda, 1993:331). Baja California estaba, entonces, en las redes dendríticas estadounidenses, francesas e inglesas, sin posibilidad de un desarrollo basado en la autotransformación. Carlos Marichal expresa cuáles fueron sus premisas materiales: “La zona sureña de Baja Cal ifornia contaba con una escasa población en el siglo XIX; pero, en cambio, disfrutaba de grandes extensiones detierras y determinados recursos naturales que tenían una demanda importante en los países económicamente más avanzados" (Marichal, 1988:20). Por eso no es casual queentre $1866 \mathrm{y}$ 1925, la bahía dePichilingue fuera usada como estación carbonera por la Marina de Guerra de los Estados Unidos.

El periodo de apogeo de la gran inversión extranjera en México, según Carlos Marichal, fue de 1880 a 1910. La revolución (1910-1920) provocó una descapitalización con inversiones sólo en la industria petrolera, la manufactura y la banca, y modificó las relaciones sociales y económicas al interior del país, las relaciones internacionales, la inversión y la inmigración. Es decir, real izó un reordenamiento delas fronteras económicas y políticas. Así, a pesar de haberse establecido las fronteras para el Estado nacional y su mercado exclusivo en el siglo XIX, como señala Héctor Cuadra, la actividad económica no se nacionalizó y siguió siendo periferia de los mercados centrales y dependiendo de sus criterios de desarrollo, no de los del Estado nacional.

En este punto es posible identificar que existían al menos tres fronteras económicas y tres mercados en Baja Cal ifornia Sur: 1) la que establecían los mercados y lugares centrales europeos y estadounidenses, dedistribución dendrítica; 2) la dela economía local detipo solar que relaciona el mercado local con el nacional y a través de las relaciones políticas con las empresas extranjeras, y 3) las economías de subsistencia, presumiblemente reticulares y relacionadas con los mercados del sistema solar, y es deesperarse, quea los dela economía informal también. 
Estas estructuras establecen un complejo entramado entre las economías locales, la de representación nacional y la mundial. Evidentemente que las economías hegemonizadoras son las del mercado internacional, vulnerando las funciones de las fronteras nacionales y su proyecto político nacional, aunque no necesariamente el degrupos económicos local es o nacional es conectados al proceso.

Esto nos permite analizar el reordenamiento de las fronteras, estructuras económicas y políticas, a partir dela revolución mexicana. Darcy Ribeiro (Ribeiro, 1978:30-31) reconoce que México logró una aceleración evolutiva a través de un nacionalismo modernizador surgido con la revolución. Esteproceso en Baja Cal iforniaSur severificó con la salida de la base carbonera estadounidense de Pichilingue en 1925, y con la reivindicación completa de las tierras comprendidas en la concesión de Delbert J. Haff y Cía. y con una política decolonización agraria, auspiciada por el gobierno del General Juan Domínguez Cota e impulsado por el programa del gobierno de Lázaro Cárdenas. Este proyecto contemplaba el desarrollo del territorio y acciones directas orientadas hacia la agricultura, los campesinos, las comunicaciones, el comercio, la industriay el crédito (Martínez, 1991:447). Pero aún no se había realizado una incorporación política del territorio al Estado nacional, lo quelimitaba cualquier intento de acceso directo, por la vía dela participación política, al proyecto nacional.

El nuevo proyecto económico y político dela posrevolución introdujo el riego por bombeo para potencial izar la agricultura. Su parteprincipal incluía 40000 hectáreas en el valledeSanto Domingo para la producción dealgodón y trigo. Seestabl eció una ley especial para regular el turismo, y en 1933 se extendió la franquicia de perímetros libres para las mercancías extranjeras a Baja California Sur. Las medidas del gobierno cardenista tenían la intención de acercar a Baja California, Baja CaliforniaSur y Quintana Roo a la fronteraeconómica, políticay cultural mexicana, reconociendo su desatención y justificándola por su situación geográfica: “Los Territorios han tenido que afrontar el problema de aislamiento que se deriva de su posición geográfica, la unidad de cultura y las relaciones deíndoleeconómica [...]" (Martínez, 1991:551).

Las medidas proponían acciones económicas, transformaciones políticas, promovían una repoblación mexicana, ofrecían protección 
estatal, incorporación a la economía nacional y defensa dela "cultura patria", para "ahorrar a la nación las responsabilidades queen el futuro lesobrevendrían si no supiera cumplir con su deber hacia las regiones peninsulares" (Martínez, 1991:551). En términos de nuestro análisis, se pretendía evitar la ruptura de la frontera decimonónica y la pérdida de los territorios. El intento de rearticular la frontera contaba con un elemento de aceleración tecnológica: la aplicación de los sistemas de riego y la incorporación de Baja California Sur al mercado nacional, creando un modelo de mercado regional agrícola que dio base a los asentamientos humanos en el valle de Santo Domingo (Ciudad Insurgentes y Constitución).

Hay que recordar quea partir de 1930, el gobierno contaba con $90 \%$ delas tierras peninsulares después de la recuperación de los terrenos dela concesión Del bert J. H aff (Preciado, 1995:50). A unado a esto, con la medida delas zonas libres, el gobierno regulaba el comercio directo con el mercado mundial, que antes se había dejado en manos de las compañías extranjeras o departiculares.

Noesel propósito deestas líneas hacer la evaluación deestemodelo de incorporación a la frontera económica nacional, eso nos distraería del objeto central de este trabajo. Por ello, daremos un sal to desde el inicio del proyecto de reordenamiento de las fronteras económicas y políticas a la actualidad, y trataremos de mostrar algunos aspectos agrícolas dela frontera económica.

Los escenarios de la frontera económica en la agricultura han cambiado. En 1993, JoséUrciaga (1993) hizo un recuento dela situación agrícola queevolucionó a partir del proyecto cardenista: Ia producción tradicional deal godón y garbanzo disminuyó, aumentó la producción de maíz y frijol, las hortalizas se diversificaron y los empresarios de este sector encontraron una base para establecerse en el estado. La razón es clara: “Ios trabajadores agrícolas apenas perciben un décimo del salario del trabajador norteamericano. La ventaja comparativa más atractiva paral os capitales norteamericanos y canadienses, y en especial para las agromaquilas, es el bajo costo de la fuerza de trabajo agrícola mexicana” (Urciaga, 1993:25). Además: “la apertura comercial y el TLC han generado un conjunto deexpectativas para quelas regiones orienten su producción agrícolaal mercado internacional" (Urciaga, 1993:26). 
Según Urciaga, Baja California Sur se orientaba al mercado internacional con la producción de hortalizas, sobre todo las que se consumen en invierno. Pero la capacidad de los agricultores locales para invertir en este mercado era limitada. A demás, la concentración de la tierra había puesto el $60 \%$ de los predios agrícolas en manos de 20 familias, y había una sobreexplotación delos pozos. Anteestecuadro, las opcioneseran: el respeto a lasnormas deuso deagua, la tecnificación del riego (aunqueno había capacidad económica para ello), la reducción de la superficie cultivada y la reorientación dela producción agrícola.

Un nuevo reordenamiento económico modificó el artículo 27 constitucional, lo que "permitiráquegrupos económicos decoinversión nacional y extranjera operen en los ejidos y en propiedad privada" (Urciaga, 1993:32). La agricultura al tamente productiva quedaría en manos delas agromaquilas decapital mixto quereal izan su mercancía en losmercados extranjeros. Así, en el marco del TLC, losagentes capaces de realizar el proceso de acumulación en la agricultura son, en orden decreciente: Ios inversionistas extranjeros (particularmente en la agromaquila hortícola), los inversionistas privados nacionales, los ejidatarios y, en menor medida, el Estado. “La iniciativa privada nacional [...] no puede competir tecnológicamente, en montos de inversión, ni en procesos decomercialización con lainversión extranjera con lo que queda claro su papel de complementariedad" (Urciaga, 1993:34-35).

Ya han pasado cuatro años deesa apreciación. El proceso queprevéa Urciaga avanza y se perci be parte desus efectos. Ramiro Serna (1997), Coordinador estatal del Programa Nacional con Jornal eros Agrícolas en Baja California Sur, expresó, en mayo de 1997, que la cantidad de jornaleros agrícolas en el estado llega hasta 20000 personas, queen La Paz y Mulegése generan 110 millones de pesos, y se ocupa el $2.5 \%$ de las ganancias en salarios. La mayoría de los jornaleros procede de Guerrero y Oaxaca, pero llegan a los campos de Baja California Sur desde los campos agrícolas de Sinal oa, generalmente. En los campos agrícolas del valle de Vizcaíno trabajan cerca de 6458 jornaleros, y en los del valle de Santo Domingo llegan a ser hasta 8390 . Las empresas agrícolas establecidas cuentan con alta tecnol ogía importada, insumos importados, exportan a los Estados Unidos, aprovechan los bajos costos 
de arrendamiento de la tierra, no tienen limitaciones para el uso de agua y sus redes de comercial ización están en California.

Tenemos, entonces, que el esfuerzo cardenista de reordenamiento dela frontera económica en Baja California Sur ha sido sustituido por otro reordenamiento económico, desistema de distribución dendrítico, con lugar central, en el caso de la horticultura, en California. Cuenta con una capacidad tecnológica que supera la capacidad de los agricultores locales y los ejidatarios que se beneficiaron del reparto agrícola, moviliza una cantidad importantedetrabajadores y es capaz deaprovechar al máximo todas las ventajas queel TLC pueda ofrecerle.

Podemos encontrar similitudes en distintos momentos históricos en la frontera económica sudcaliforniana: su mercado dendrítico -organizado por empresas de al ta tecnología aprovechando los recursos natural es de la región - y la fuerza de trabajo jornalera. Si el proyecto cardenista dereordenamiento económico contemplaba acercar a las penínsulas al mercado nacional, los procesos del mercado y la constitución de fronteras económicas parecieran tener un efecto contrario.

Lafrontera económica searticula a través delas redes comercialesy la jerarquización de lugares centrales, gracias a la permeabilidad económica y política del mercado y del estado sudcaliforniano, y por la capacidad técnica y económica de quienes organizan los mercados en los centros rectores. Las condiciones geográficas, económicas y políticas han orientado a este subsistema económico del Estado mexicano a ser periferia política y económica del sistema político y económico nacional y periferia delos mercados extranacionales.

El establecimiento delas agromaquilas conecta los procesos agrícolas y productivos del noroeste (puesto quelos productoreshortofrutícolas están relacionados con esta región) al mercado estadounidense; es decir, establecen una nueva frontera económica, demercado, hacia eselugar central. Evidentemente, la reorganización de los mercados en los subsistemas económicos provoca un reajuste de las fronteras económicas y éstas, a su vez, traen consigo reordenamientos de las políticas del estado en relación con sus fronteras y subsistemas económicos. Así, para mantener dentro de su sistema político los procesos que allí se verifican, a esas fronteras las harán más o menos 
permeables. Ésa es la lógica que aparenta seguir el proceso iniciado antes de 1988, y que se hace más evidente a partir de ese año con las medidas políticas y económicas de apertura formal de la economía e inicio de un proceso de integración al mercado del bloque estadounidense, para competir con los otros bloques. El reordenamiento crea condiciones para una partici pación nacional delos subsistemas regida por acuerdos internacionales. Esto tiene como consecuencia inmediata la definición de políticas de regulación al interior del Estado nacional que procurará integrar otros subsistemas a esta estrategia nacional y de bloque. Para Baja California Sur, esta apertura ya estaba hecha en el terreno agrícola desde la década de los ochenta. La nueva frontera de la globalización y el TLC se parece bastante a la frontera económica a la que ya estaba integrándose el agro en Baja California Sur. Faltaría ver susimplicaciones en el turismo, la pesca, la minería y las salinas.

En efecto, no hemos analizado el enclave turístico de Los Cabos, que cumple funciones tal vez similares y otras distintas en términos del verdadero significado económico que pueda tener este enclave. Tampoco hemos analizado el caso de las salinas de Guerrero N egro, quea nuestro parecer responde también a otro sistema dendrítico de mercado, como tampoco la situación de la pesca que se orienta igualmente hacia el mercado internacional. Estos temas también deberían ser estudiados en perspectiva histórica antelas premi sas que impone la redefinición de las nuevas fronteras económicas en Baja California Sur. Así, el estudio de la sal y el paisaje son, entre otras, tareas pendientes a considerar en una investigación sobre las implicaciones regional es del nuevo paradigma de la frontera.

El espacio regional y el subsistema económico delo quehoy es Baja California Sur ha sido accesible a mercados y economías centrales extranacional es las más de las veces a partir de acuerdos legalmente establecidos, de lo que se infiere que ésa ha sido su función como subsistema económico regional en el contexto económico nacional. Este proceso fue alcanzado por el reordenamiento económico y político actual queseenmarca jurídicamenteen el TLC y lo que podría llamarse un proceso civilizatorio deactualización histórica: la gl obalización. Pero todo pareceindicar quelo quehoy sellama gl obalización, transferencia 
de tecnología e incorporación a mercados internacionales, ha estado ocurriendo en Baja Cal ifornia Sur, por lo menos, desde mediados del siglo XIX. La frontera económica sudcal iforniana y su desarrollo han dependido de las integraciones y desintegraciones de mercados y de la casi siempre permeable frontera política mexicana que ha fracasado en fomentar un desarrollo más amplio y una incorporación más activa dela región a la vida nacional.

\section{CONCLUSIÓN}

Desdeel punto devista económico, cultural y natural , el viejo concepto de frontera política es limitado para explicar la realidad actual antela globalización. Si bien estefenómeno, entendido como una importante cantidad de intercambios internacionales, no es nuevo - data por lo menos del sigloXV - (Dollfus, 1997:10-13), sí lo es en las dimensiones eintensidad contemporáneas.

Sin embargo, las fronteras decimonónicas - las de los Estadonación- lejos de tender a la extinción, sirven como sustento a las intrincadas redes de la mundialización. Es menester mantener los espacios nacionales bien diferenciados, de otra manera, las ventajas comparativas que incitan la exacerbación de la mundialización tenderían a el iminarse, y con esto, a contravenir a la existencia misma del fenómeno.

Todo se clarifica cuando comprendemos la verdadera natural eza del proceso: las fronteras políticas se encuentran avasalladas ante las redes dela economía internacional. Las nuevas fronteras económicas, cuyos espacios ni por asomo seasemejan a los delas fronteras políticas, transforman profundamentetodos los ámbitos dela existencia, lo que explicala necesaria redefinición delas fronteras culturales y naturales, ya que, lejos de desaparecer, sólo se han transformado.

Retomand o el estudio del caso queempíricamentenos ha ocupado, podemos constatar que la frontera económica sudcaliforniana y su desarrollo han dependido de integraciones y desintegraciones de mercados y de la casi siempre permeable frontera política que no ha podido organizar un desarrollo más amplio y una incorporación más activa de la región a la vida nacional. La nueva frontera económica 
nacional no es tan nueva para Baja CaliforniaSur, en especial en lo que se refiere al uso de los recursos naturales. Ya se han señalado las limitaciones de la nueva frontera económica; éstas pueden generar situaciones particularmente duras en zonas que siguen siendo periféricas para su centro político. El reordenamiento económico de los subsistemas y de la política nacional implica reordenamientos importantes tanto legales como de la percepción del fenómeno desde la sociedad civil, lo quehaceimportantela participación dela opinión pública.

El desarrollo de la nueva frontera económica apunta hacia una actualización histórica que, evidentemente, puedetener implicaciones negativas, pero podría traer consigo procesos de desarrollo propio cultural, económico, político, tecnológico, informático y organizacional en los escenarios de esta nueva frontera, que permitan activaciones sociales que el mismo proceso económico acelera. La globalización y sus medios el ectrónicos y técnicos van a cumplir un papel importante no sólo en la organización de la nueva frontera económica, sino en el reordenamiento social que debedarse. Las herramientas técnicasy de comunicación de la nueva frontera económica van a jugar -y ya juegan- un papel importante en el reordenamiento de la frontera política, cultural y social.

La conformación de los nuevos mercados, de actualización técnica e histórica, está definiendo fronteras económicas, pero también las políticas sociales y cultural es y sus escenarios. El problema es degran interés porque, en el caso mexicano, la conformación deestas fronteras, aunado a la situación política y económica internacional, generaron las condiciones para cambios en las relaciones México-Estados Unidos. Esto, a su vez, tuvo gran peso en la formulación de reordenamientos económicos y políticos en A mérica Latina después de la guerra fría.

El caso sudcal iforniano deutilización desus recursos naturales y el de su agricultura es parte de los reordenamientos de la frontera económica. Éstos han establecido las pautas y las prácticas económicas quecondujeron a un reordenamiento económico nacional y desataron procesos de reordenamiento económico en A mérica Latina, de ahí la importancia de su estudio. 


\section{BIBLIOGRAFÍA}

Braudel, Fernand (1953). “Geohistoria y determinismo” conclusión de la primera parte deEI M editerráneo y el mundo mediterráneo en la época de Felipell, 1ạ. Ed. En español, FCE, México.

(1979). Civilisation M atérielle, Economieet Capitalisme, XvèXVIIIè Siècle, A rmand Colin, París, 3 vols.

(1989). Historia y ciencias sociales, A lianza Universidad, México. Breceda, Aurora y Michel ine Cariño (1995). Ecohistoria delos californios, UABCS, LaPaz.

Cariño O., Micheline (1995). “El saqueo de la flora silvestre sudcal iforniana (1870-1940)", U niversidad M ichoacana, núm. 17, julio-septiembre, Morelia.

(1996a). “Concesiones territoriales a la inversión extranjera en Subcalifornia durante el siglo XIX", Inversiones y empresarios extranjeros en el noroccidentede M éxico en el siglo XIX , Javier Olveda (ed.), El Colegio de Jalisco, México.

(1996b). H istoria delas relaciones hombre/naturaleza en Baja California Sur, 1500-1940, UABCS, SEP-Fomes, La Paz.

Castañeda, JorgeG. (1993). La utopía desarmada, Joaquín M ortiz-Planeta, México.

Cuadra, Héctor (1997). “Globalización”, Conferencia magistral, Foro sobre Jornaleros Agrícolas Migrantes, UABCS, La Paz, Baja California Sur, 28, 29y 30 de mayo.

Diccionario Enciclopédico A rgos V ergara (1977). Editorial A rgos Vergara. Dollfus, Olivier (1997). "Les espaces de la mondialisation", Sciences

H umaines, Hors Serie, núm. 17, junio-julio, Francia.

González de Molina, Manuel y Juan Martínez Alier (1993). Historia y ecología, A yer, núm. 11, Madrid.

Guhl, Ernesto (1991). Escritos geográficos. Las fronteras políticas y los límites naturales, Fondo fEN Colombia, Bogotá.

Herrera Carrillo, Pablo (1976). Colonización del valle de M exicali, UABC, Mexicali, B.C. México.

Lepetit, Bernard (1996). “Espacio e historia. Homenaje a Fernand Braudel", artículo traducido del francés por Micheline Cariño, 
Clio, revista de la Escuela deHistoria, UAS, núm. 18, septiembrediciembre, Cualiacán, Sinaloa.

Marichal, Carlos (1988). “ Introducción”, Inversiones y empresarios extranjeros, México

Martínez, Pablo L. (1991). Historia de la Baja California, gobierno del estado de Baja California Sur, La Paz.

Panian, Henry (1996). “La concesión Lesse” en Esteban Ojeda Ramírez (comp.) A ntología de historia regional para la educación media, La Paz, Baja CaliforniaSur, México, SEP-Gobierno del estado deBaja CaliforniaSur.

Pastor, Robert (1995). El remolino, política exterior deEstados U nidos hacia A mérica Latina y el Caribe, siglo XXI, México.

Preciado Llamas, Juan (1995). “Política agraria y conflictos por latierra en el Territorio Sur de la Baja California durante el periodo cardenista", R evista del nvestigación Ciencias Sociales y H umanidades, UABCS, LaPaz.

Raumolin, J. (1984). “L'homme et la destruction des Ressources Naturelles: la Raubwirtschaft au tournant du siècle", Annales E.S.C. 39(4), París.

Ribeiro, Darcy (1978). La cultura latinoamericana, UNAM, México.

Sciences H umaines (1997). Hors Serie, núm. 17, junio-julio.

Serna, Ramiro (1997). “Jornaleros agrícolas en Baja California Sur, una experiencia en proceso", conferencia magistral en el Foro sobre jornaleros agrícolas migrantes, 28, 29y 30 demayo, UABCS, LaPaz. Smith, Carol (1991). "Sistemas económicos regionales: modelos geográficos y problemas socieconómicos combinados", Región e historia en M éxico (1700-1850), Pedro Herrero (comp.), A ntologías Universitarias, Instituto M ora, UAM, México.

Southworth, J.R. (1989). Baja California ilustrada, Gobierno del estado deBaja California Sur, La Paz.

Toynbee, Arnold J. (1991). Estudio de la historia, Alianza Ed. Madrid, 3 vols.

Urciaga, José (1993). “Situación actual y perspectiva del desarrollo agrícola en Baja Cal ifornia Sur", Revista de Investigación Ciencias Sociales y H umanidades, núm. 1, otoño-invierno, nueva época, UABCS, LaPaz. 
Veyret, Yvette y Pierre Pech (1993). I'homme et I'environnement, PUF, París.

Wallerstein, Immanuel (1974). The M odern W orld System, Academic Press, Nueva York.

Weber, David (1991). “Turner, los boltonianosy lastierras defrontera”. En: Francisco Solano y Salvador Bernabeu, Estudios (nuevos y viejos) sobre la frontera, CSIC-CH-Departamento de Historia de A mérica, Madrid.

Wiggins, I. L. (1980). Flora of Baja California, Stanford University Press. 